Article

\title{
A Long-Acting Curcumin Nanoparticle/In Situ Hydrogel Composite for the Treatment of Uveal Melanoma
}

\author{
Lingxiao Xie ${ }^{1}$, Weizhou Yue ${ }^{1}$ (D) , Khaled Ibrahim ${ }^{1}$ id and Jie Shen ${ }^{1,2, *}$ \\ 1 Department of Biomedical and Pharmaceutical Sciences, University of Rhode Island, \\ Kingston, RI 02881, USA; lingxiao_xie@uri.edu (L.X.); weizhou_yue@uri.edu (W.Y.); \\ khaled_ibrahim@uri.edu (K.I.) \\ 2 Department of Chemical Engineering, University of Rhode Island, Kingston, RI 02881, USA \\ * Correspondence: jie_shen@uri.edu; Tel.: +1-401-874-5594
}

check for updates

Citation: Xie, L.; Yue, W.; Ibrahim, K.; Shen, J. A Long-Acting Curcumin Nanoparticle/In Situ Hydrogel Composite for the Treatment of Uveal Melanoma. Pharmaceutics 2021, 13, 1335. https://doi.org/10.3390/ pharmaceutics13091335

Academic Editors: Anuj Chauhan, Laurence Fitzhenry, Ana Paula Serro and Monica M. Jablonski

Received: 23 June 2021

Accepted: 22 August 2021

Published: 25 August 2021

Publisher's Note: MDPI stays neutral with regard to jurisdictional claims in published maps and institutional affiliations.

Copyright: (c) 2021 by the authors. Licensee MDPI, Basel, Switzerland. This article is an open access article distributed under the terms and conditions of the Creative Commons Attribution (CC BY) license (https:/ / creativecommons.org/licenses/by/ $4.0 /)$.

\begin{abstract}
Uveal melanoma (UM) is the most common primary intraocular tumor in adults with high mortality. In order to improve prognosis and survival of UM patients, it is critical to inhibit tumor progression and metastasis as early as possible after the initial presentation/diagnosis of the disease. Sustained local delivery of antitumor therapeutics in the posterior region can potentially achieve long-term UM inhibition, improve target therapeutic delivery to the posterior segments, as well as reduce injection frequency and hence improved patient compliance. To address the highly unmet medical need in UM therapy, a bioinspired in situ gelling hydrogel system composed of naturally occurring biopolymers collagen and hyaluronic acid was developed in the present research. Curcumin with anti-cancer progression, anti-metastasis effects, and good ocular safety was chosen as the model therapeutic. The developed in situ gelling delivery system gelled at $37^{\circ} \mathrm{C}$ within two minutes and demonstrated excellent biocompatibility and slow degradation. The curcuminloaded nanoparticle/hydrogel composite was able to sustain release payload for up to four weeks. The optimized nanoparticle/hydrogel composite showed effective inhibition of human UM cell proliferation. This novel nanoparticle/in situ hydrogel composite demonstrated a great potential for the treatment of the rare and devastating intraocular cancer.
\end{abstract}

Keywords: in situ hydrogel; nanoparticle/hydrogel composite; sustained delivery; curcumin; uveal melanoma

\section{Introduction}

Uveal melanoma (UM) is considered a rare disease yet the most common primary intraocular tumor with high metastasis and lethality in adults [1,2]. Treatment modalities including globe-preserving therapies (e.g., proton beam radiotherapy, plaque brachytherapy) and enucleation have been commonly used. Despite the aggressive treatment strategies, a high recurrence rate, in particular following transscleral resection (up to $32.6 \%$ ), has remained a challenge [3-5]. Moreover, nearly a half of UM patients eventually developed metastatic diseases (primarily in the liver) that are resistant to systemic chemo- and immunotherapy, leading to poor prognosis and high mortality [6]. Up to now, there has been a lack of effective treatment to prevent UM metastasis. Accordingly, it is considered that early detection and intervention may be critical to improve prognosis and survival of UM.

The uvea is one of the most capillary-rich tissues of the body. Most UM occurs in the posterior segments such as choroid $(\sim 90 \%)$, iris $(\sim 5 \%)$ and ciliary body $(\sim 5 \%)[7,8]$. Due to the lack of lymphatic vessels in the choroid, primary UM metastasizes almost exclusively via the hematogenous route $[9,10]$. As a result, effective suppression of molecular mechanisms that activate angiogenesis, tumor cell mobility and invasion, has demonstrated the potential in improving UM therapy [11-13]. For example, regulator or knockdown hypoxia-response regulating genes cyclic AMP-response-element binding protein and hypoxia-inducible factors-1 (HIF-1), vascular endothelial growth factor (VEGF) can 
markedly decreased UM cell or tumor growth [14-18]. However, the presence of anatomical ocular barriers (e.g., cornea, blood-retina barrier) and physiological constraints (e.g., nasolacrimal drainage, limited capacity in the cul-de-sac of the eye) prevents about $99 \%$ of drug administrated systemically and topically to reach the posterior segments [19]. Local delivery of therapeutics in the posterior chamber (e.g., via intravitreal administration) can circumvent these barriers to directly target the tumor in the posterior chamber to improve anti-UM effect while reducing off-target toxicity. As most therapeutics require frequent dosing due to their short half-lives in the vitreous humor, a long-acting local delivery platform that can sustained deliver therapeutics in the posterior chamber is considered desirable to improve therapeutic effect and patient compliance for the UM treatment.

Various nanocarriers/microcarriers with sustained drug delivery capability have been developed in recent years for ocular use [20,21]. Due to their size, and flexible surface functionality, nanocarriers/microcarriers offer advantages in drug delivery for the treatment of posterior eye diseases [22,23]. However, there are disadvantages associated with nanocarriers/microcarriers directly administrated in the posterior chamber, including potential toxicity due to high burst drug release; rapid phagocytic clearance which may decrease therapeutic effect; particle aggregation due to large surface area; and particle migration which may cause ocular inflammation [23]. Currently, marketed long-acting intravitreal implant drug products (e.g., Ozudex ${ }^{\circledR}$, Iluvien ${ }^{\circledR}$ ) are able to sustain deliver therapeutics in the posterior segments over weeks to months. These implant products are administrated via either an injector/applicator with a large size needle (i.e., 22-gauge) or surgical procedures and hence poor patient compliance. Over the past decade, in situ gelling hydrogels that can be injected as solutions via fine needles (i.e., 30-gauge or smaller) and transform to gels/depots at the injection site, have attracted increasing interests due to excellent injectability and improved patient compliance [24-26]. However, the use of synthetic polymer-based hydrogels (e.g., polystyrene, poloxamer) has limited its applications due to concerns on biodegradability and potentially triggering inflammatory response and influencing retinal function [25,27]. Moreover, a crosslinking initiator or catalyst (such as a metal catalyst, or photoinitiator) or ultraviolet (UV) light is often needed to facilitate polymer crosslinking and gelation, which raises biocompatibility concerns [28-30]. Accordingly, it is essential to develop a biodegradable and biocompatible in situ forming hydrogel platform that gels within seconds to minutes and is capable of releasing payload over weeks to months.

The vitreous body is mainly composed of hyaluronic acid and different types of collagens, primarily type II collagen [31,32]. Inspired by the natural components of the vitreous body, an in situ gelling hydrogel delivery platform composed of naturally occurring biopolymers such as hyaluronic acid (HA) and collagen (type II) was developed to sustained release payload for UM therapy in the present research. The in situ gelling hydrogel system provides easy administration, prolongs retention time, and prevents drug/particle migration. Curcumin with good ocular safety was chosen as the model therapeutic. It has been reported curcumin can regulate hypoxia-inducible factors- $1 \alpha$ (HIF- $1 \alpha)$ in hepatocellular carcinoma cells, pituitary adenomas, and inhibits angiogenesis in zebrafish [33-36]. Curcumin also showed anti-proliferation and down-regulation of the expression of genes involved in apoptosis, cell proliferation and transformation against various cancers (e.g., breast cancer, lung cancer, colorectal cancer) [37-41]. Moreover, curcumin has been shown to induce cell death in human UM cells via the mitochondrial pathway [42]. As curcumin is poorly water soluble, curcumin-loaded nanoparticles with a hydrophilic coating layer were fabricated to improve its vitreous transport and cellular uptake. The curcumin-loaded polymeric nanoparticles were incorporated in the collagen II and HA hydrogel (CO-HA Gel) matrix. The rheological properties, payload release as well as in vitro anti-UM effect of the developed curcumin nanoparticle/in situ hydrogel composites were investigated. 


\section{Materials and Methods}

\subsection{Materials}

Collagen (type II) from calf articular joints was purchased from Elastic Products Company, Inc (Owensville, MO). Sodium hyaluronate (HA, molecular weight (MW): 15 MDa) was purchased from Lifecore Biomedical (Chaska, MN, USA). Eight-arm polyethylene glycol (PEG) succinimidyl glutarate (tripentaerythritol) (8-arm PEG, MW: 20 kDa and $40 \mathrm{kDa}$ ) were purchased from JenKem Technology USA (Plano, TX, USA). Picrylsulfonic acid solution (TNBS), polysorbate (Tween) 80, N-acetylcysteine (NAC), butylated hydroxytoluene (BHT), glycine (ReagentPlus ${ }^{\circledR}, \geq 99 \%$ ), dichloromethane (DCM, ACS reagent, $\geq 99.5 \%$ ), poly(vinyl alcohol) (PVA, 87-90\% hydrolyzed, MW: 30-70 kDa), sucrose $(\geq 99.5 \%)$, collagenase from clostridium histolyticum $(1.5 \mathrm{kU})$, hyaluronidase (type II) from sheep testes, dimethyl sulfoxide (DMSO, ACS reagent, $\geq 99.9 \%$ ), acetonitrile (HPLC grade, $\geq 99.9 \%$ ), trifluoroacetic acid (TFA, HPLC grade, $\geq 99.0 \%$ ) were purchased from Sigma-Aldrich (St. Louis, MO, USA). Curcumin was purchased from TCI Chemicals (Portland, OR, USA). Methoxypoly(ethylene glycol)-b-poly(lactide-co-glycolide) (mPEG-PLGA, L/G: 50/50, w/w; MW: $5 \mathrm{kDa} / 55 \mathrm{kDa}$ ) was purchased from PolySciTech ${ }^{\circledR}$, Akina, Inc. (West Lafayette, IN, USA). LIVE/DEAD ${ }^{\mathrm{TM}}$ viability/cytotoxicity kit (for mammalian cells), CyQUANT $^{\mathrm{TM}}$ MTT cell viability assay, phosphate-buffered saline (PBS, pH 7.4), trypsinEDTA (0.25\%) phenol red, 4-(2-hydroxyethyl)-1-piperazineethanesulfonic acid (HEPES, $1 \mathrm{M})$ and penicillin-streptomycin $(10,000 \mathrm{U} / \mathrm{mL})$ were purchased from Thermo Fisher Scientific (Waltham, MA). RPMI-1640 medium (ATCC ${ }^{\circledR} 30-2001^{\mathrm{TM}}$ ) and fetal bovine serum (FBS) (ATCC ${ }^{\circledR}$ 30-2020 ${ }^{\mathrm{TM}}$ ) were purchased from ATCC (Manassas, VA, USA).

Human uveal melanoma (UM) cell line MP-38 (ATCC ${ }^{\circledR}$ CRL-3296) was grown and maintained in RPMI-1640 media with $20 \%(v / v)$ FBS and $1 \%(v / v)$ penicillin-streptomycin. Cells were cultured in an incubator supplied with $5 \% \mathrm{CO}_{2}$ at $37^{\circ} \mathrm{C}$. The culture medium was replaced every 2-3 days.

\subsection{Preparation of Curcumin-Loaded Nanoparticles}

Curcumin-loaded polymeric nanoparticles (Cur NP) were prepared via an emulsionsolvent-evaporation method as previously reported [43]. Briefly, curcumin and mPEGPLGA (curcumin/mPEG-PLGA = 1:7.5, $w / w$ ) were dissolved in $2 \mathrm{~mL}$ of DCM. The organic phase was added into $10 \mathrm{~mL}$ of an aqueous phase containing $1 \%(w / v)$ PVA to form a primary emulsion. Following size reduction via probe sonication, DCM was removed by evaporation and the residual solvent was further removed under reduced pressure. The resultant NP suspension was then filtered using a $0.22 \mu \mathrm{m}$ filter (polytetrafluoroethylene, PTFE). NP was purified via ultra-centrifugation at $229,600 \times g$ for $1 \mathrm{~h}$ with distilled (DI) water three times. The concentrated NP suspension was then lyophilized using sucrose as the cryoprotectant (sucrose/NP: 25/1, w/w). The lyophilized NP was stored at $4{ }^{\circ} \mathrm{C}$ until further use.

\subsection{Characterization of Cur NP}

Lyophilized Cur NP was accurately weighed, and curcumin was extracted using $200 \mu \mathrm{L}$ of DMSO followed by acetonitrile dilution to $2 \mathrm{~mL}$. The sample was then filtered using a $0.22 \mu \mathrm{m}$ syringe filter (PTFE) and curcumin content was determined via HPLC (Hitachi) with a ZORBAX Eclipse XDB C18 column $(5 \mu \mathrm{m}, 250 \times 4.6 \mathrm{~mm})$ (Agilent Technologies, Inc. Santa Clara, CA, USA). The HPLC mobile phase consisted of $0.1 \%$ TFA in water and acetonitrile $(40 / 60, v / v)$ with a flow rate of $1 \mathrm{~mL} /$ minute. The effluent was monitored at the wavelength of $420 \mathrm{~nm}$. The retention of curcumin was around $5.2 \mathrm{~min}$. The detection and quantification limits of the HPLC analytical method were 0.027 and $0.083 \mu \mathrm{g} / \mathrm{mL}$, respectively. Curcumin loading was calculated using the following Equation (1):

$$
\text { Dug loading }(\%)=\frac{\text { Curcumin amount in nanoparticles }}{\text { Lyophilized nanoparticle weight }} \times 100
$$


The particle size and size distribution (polydispersity index, PDI), and surface charge of NP before and after lyophilization were characterized using Zetasizer Nano ZS90 (Malvern Instruments Ltd., Malvern, UK). The backscattering angel was $173^{\circ}$ with a standard laser wavelength $\lambda$ of $633 \mathrm{~nm}$. The measurement of dynamic diameter $\left(\mathrm{D}_{\mathrm{H}}\right)$ is according to the Stokes-Einstein equation as a function of the diffusion coefficient (D), temperature $(T)$, and viscosity $(\eta)$. The measurements were carried out in triplicate.

\subsection{Fabrication of $\mathrm{CO}-\mathrm{HA}$ Gels and Composites}

A HA solution in PBS (10 mM, pH 7.4) $(5 \mathrm{mg} / \mathrm{mL})$ was mixed with a collagen II solution in a phosphate buffer $(20 \mathrm{mM}, \mathrm{pH} 7.4)(5 \mathrm{mg} / \mathrm{mL})$ at an optimized volume ratio of 3/1 (HA/collagen). An 8-arm PEG solution in PBS (10 mM, pH 7.4) $(200 \mathrm{mg} / \mathrm{mL})$ was then added into the mixture at a volume ratio of $1 / 13.5$, and the blank hydrogel $(\mathrm{CO}-\mathrm{HA}$ Gel) was formed when incubating the mixture at $37^{\circ} \mathrm{C}$.

To form NP/CO-HA Gel composite, accurately weighed NP (either blank or Cur NP) was added into the collagen II solution prior to mixing with other gel components (i.e., HA and PEG). The NP/CO-HA Gel composite was then formed following the similar procedure described above for the blank CO-HA Gel. To form curcumin/hydrogel composite (Cur/CO-HA Gel), a curcumin solution in ethanol $(2.424 \mathrm{mg} / \mathrm{mL})$ was mixed with the gel components (i.e., collagen II, HA and PEG) and the mixture was then incubated at $37^{\circ} \mathrm{C}$.

\subsection{Rheological Study of Blank CO-HA Gels and NP/CO-HA Gel Composites}

Rheological properties of blank CO-HA Gel composed of different MW PEG with or without NP were determined using a TA Discovery HR-2 rheometer (TA Instruments, New Castle, DE) with a cone shape geometry $\left(40 \mathrm{~mm}, 2^{\circ}\right)$. After mixing three gel components (i.e., collagen, HA and PEG) at the ratios described in Section 2.4, $800 \mu \mathrm{L}$ of the mixture was immediately loaded onto a sample loading plate pre-equilibrated at $25^{\circ} \mathrm{C}$. The cone shape geometry was lowered to a pre-determined gap $(48 \mu \mathrm{m})$ to obtain a vertical side wall. Oscillation amplitude analysis was performed at $37^{\circ} \mathrm{C}$ to determine a linear viscoelastic region (LVR) at a frequency of $1 \mathrm{~Hz}$. Gelling time of hydrogels was determined via time sweep with $1 \mathrm{~Hz}$ frequency and $5 \%$ strain in $20 \mathrm{~min}$ at $37^{\circ} \mathrm{C}$. Storage modulus of the $\mathrm{CO}-$ HA Gel was obtained by unconfined compression measurements with oscillation frequency ranging from 0.1 to $10 \mathrm{~Hz}$ at $5 \%$ strain at $37^{\circ} \mathrm{C}$. The CO-HA Gel and NP/CO-HA Gel composites were placed between a solid plate and the rheometer geometry, and freely expanded laterally during the dynamic compression. The measurements were carried out in triplicate.

\subsection{Crosslinking Density Study}

The crosslinking degree of the CO-HA Gel was calculated based on the rubber elasticity theory using experimental storage modulus $\mathrm{G}^{\prime}$ as reported previously [44]. The number of elastically active junctions in the network per unit of volume $\left(n_{e}, \mathrm{~mol} / \mathrm{m}^{3}\right)$ was calculated using the following Equation (2):

$$
G^{\prime}=n_{e} R T
$$

where $G^{\prime}$ is storage modulus, $R$ is the gas constant, and $T$ is the absolute temperature.

\subsection{Determination of Swelling Property}

Disc-shaped CO-HA Gel samples were formed in a 96-well plate in triplicate. The sample was transferred into an Eppendorf tube and weighed on a microscale (Mettler Toledo, Greifensee, Switzerland) to obtain the initial weight $\left(W_{i}\right)$. The sample was then immersed in saline and incubated at $37^{\circ} \mathrm{C}$ to allow free swelling for $48 \mathrm{~h}$. The sample was taken out and excess saline was gently removed. Fully swollen samples $\left(W_{s}\right)$ were weighed on a microscale and lyophilized (FreeZone Triad Cascade Benchtop Freeze Dryer, 
LABCONCO, Kansas City, MO, USA). Hydrogel swelling was calculated based on mass change percentage $(\%)$ using the following equation:

$$
\text { Mass increase }(\%)=\frac{W_{S}-W_{i}}{W_{i}} \times 100 \%
$$

The weight $\left(W_{d}\right)$ of the freeze-dried hydrogels was also determined, and the equilibrium water content $(E W C)$ was calculated using the following equation:

$$
E W C=\frac{W_{s}-W_{d}}{W_{s}}
$$

\subsection{Morphology/Internal Structure of Cur NP and NP/CO-HA Gel Composites}

Lyophilized Cur NP was transferred to a metal substrate with double-sided carbon tape. A thin film of Au was sputtered coated onto the NP for $30 \mathrm{~s}$. The sample was then imaged using SIGMA VP Field Emission-scanning electron microscope (FE-SEM) (ZEISS, Oberkochen, Germany). Hydrogel samples were imaged via cryo-SEM. The blank CO-HA Gel sample was formed and frozen in liquid nitrogen and attached to the specimen holder of a cryo-transfer system. The sample was transferred onto a cryostage in the SEM system and cross-sectioned, and subsequently transferred to a SEM sample stage and examined via FE-SEM. The structure of Cur NP/CO-HA Gel composite was also examined using cryo-transmission electron microscopy (cryo-TEM). Small pieces of Cur NP/CO-HA Gel composite were transferred on a TEM copper grid. The grid was quickly immersed in liquid ethane. The frozen-hydrated specimens were mounted on a cryo-holder and observed using JEM-2100 TEM (JEOL USA, Inc, Peabody, MA, USA). The obtained images were analyzed by image J find edge process and threshold. The $\%$ of mesh area and mesh size were analyzed by area fraction and ferret's diameter function, respectively. Mesh size diameters $D_{90}, D_{50}$, and $D_{10}$ were obtained by excel percentile function. Diameter span was calculated using the following equation:

$$
\text { Span }=\frac{D_{90}-D_{10}}{D_{50}}
$$

\subsection{In Vitro Degradation Study}

In vitro degradation of $\mathrm{CO}-\mathrm{HA}$ Gels was investigated by incubating formed hydrogels $(300 \mu \mathrm{L})$ in $300 \mu \mathrm{L}$ of saline at $37^{\circ} \mathrm{C}$ in triplicate. At pre-determined time intervals, the hydrogels were removed and gently washed with DI water. The remaining free amine groups in the hydrogel were determined using a spectrophotometric method [45,46]. Briefly, $187 \mu \mathrm{L}$ of $0.1 \%(w / v)$ TNBS diluted with $0.1 \mathrm{M} \mathrm{NaHCO}_{3}$ were added into the hydrogel samples and incubated for $2 \mathrm{~h}$ at $37^{\circ} \mathrm{C}$. The reaction was ceased by adding $563 \mu \mathrm{L}$ of $6 \mathrm{~N}$ $\mathrm{HCl}$ to the samples followed by autoclave for $1 \mathrm{~h}$ at $120^{\circ} \mathrm{C}$. After the samples were cooled down to room temperature, the mixture was then spectrophotometrically measured at an absorbance wavelength of $340 \mathrm{~nm}$ using a microplate-reader (Spectramax M2 MultiMode microplate reader, Molecular Devices, LLC, San Jose, CA, USA). The free amine group content was calculated based on a standard curve prepared using glycine standards. The total free amine group content $\left(\mathrm{Con}_{\text {Total }}\right)$ was determined using the same amount of collagen II prior to the degradation study. Percentage (\%) of free amine groups in the formed hydrogel was calculated based on the Equation (6):

$$
\text { Free amine group }(\%)=\frac{\text { Con }_{\text {Sample }}}{\text { Con }_{\text {Total }}} \times 100 \%
$$

In vitro degradation of CO-HA Gels $(300 \mu \mathrm{L})$ was also studied in the presence of enzymes, including $22.5 \mathrm{U}(75 \mathrm{U} / \mathrm{mL})$ collagenase and $5 \mathrm{U}(16.7 \mathrm{U} / \mathrm{mL})$ hyaluronidase in $300 \mu \mathrm{L}$ of saline at $37^{\circ} \mathrm{C}$ in triplicate. The hydrogels incubated in saline without the presence of enzymes at $37^{\circ} \mathrm{C}$ were studied as control group. 


\subsection{In Vitro Release Study of Cur NP/CO-HA Gel Composites}

In vitro curcumin release characteristics from Cur NP/CO-HA Gel composites were studied in triplicate. The composite $(200 \mu \mathrm{L})$ was immersed in $200 \mu \mathrm{L}$ of saline containing $10 \%(w / v)$ Tween $80,0.1 \%(w / v)$ NAC, and $0.01 \%(w / v) \mathrm{BHT}$, and incubated at $37^{\circ} \mathrm{C}$ in a water bath with shaking at $45 \mathrm{rpm}$. At pre-determined time points, $150 \mu \mathrm{L}$ of release media was withdrawn and replenished with fresh media. The released curcumin amount was analyzed by HPLC. The percentage of cumulative curcumin released was calculated.

\subsection{In Vitro Anti-UM Study of Cur NP/CO-HA Gel Composites}

Anti-UM study of Cur NP/CO-HA Gel composite was conducted by using transwell insert $(6.5 \mathrm{~mm}$ diameter with $8.0 \mu \mathrm{m}$ pore polyester membrane, Corning Life Sciences, Corning, NY, USA). MP-38 cells were seeded in a 24-well plate $\left(8 \times 10^{4}\right.$ cells per well $)$ and incubated for $24 \mathrm{~h}$ till confluency reached around $80 \%$. Cur NP/Gel 1, BLK NP/Gel 1, Cur/Gel 1 and Cur NP suspension (curcumin concentration: $201.0 \mu \mathrm{g} / \mathrm{mL}$ ) were tested. The gel mixture $(100 \mu \mathrm{L})$ was transferred into a transwell insert chamber and incubated in a $37^{\circ} \mathrm{C}$ incubator to form the composites. The insert was then placed in the 24-well plate seeded with MP-38 cells and completely immersed in the culture medium. For the Cur $\mathrm{NP}$ suspension group, $100 \mu \mathrm{L}$ of suspension (without hydrogel components) was added into a transwell insert before the insert was placed into a 24 -well plate. The cells seeded on the 24-well plate with the transwell inserts containing different treatments were then cultured at $37^{\circ} \mathrm{C}$ for 3 days. Following the treatment, the transwell inserts were removed and cells were washed with PBS three times. CyQUANT ${ }^{\circledR}$ MTT reagents (Thermo Fisher Scientific, Waltham, MA, USA) were prepared and added into the 24-well plate following the manufacturer's protocol. The absorbance of the samples at $570 \mathrm{~nm}$ was determined using a microplate reader. MP-38 cells without any treatment grown in the RPMI-1640 medium were studied as control. Cell viability was calculated based on the equation below:

$$
\text { Cell viability }(\%)=\left(\frac{O D_{\text {sample }}}{O D_{\text {Control }}}\right) \times 100 \%
$$

In order to further demonstrate the anti-UM effect was due to the sustained curcumin release from the NP/CO-HA Gel composites, MP-38 cells were directly cultured on the surface of the CO-HA Gels and BLK NP/CO-HA Gel composites. MP-38 cells directly grown in a culture plate without Gels was studied as control. Tested composites ( $40 \mu \mathrm{L})$ were mixed at the ratios described in Section 2.4 and transferred into a 96-well plate. The 96-well plate was incubated at $37^{\circ} \mathrm{C}$ for $30 \mathrm{~min}$. After the CO-HA Gel and composites were well formed, $150 \mu \mathrm{L}$ of RPMI-1640 medium without FBS was added into the wells and incubated for $2 \mathrm{~h}$ at $37^{\circ} \mathrm{C}$. The medium was then removed and replaced with $150 \mu \mathrm{L}$ of fresh RPMI-1640 medium contained 20\% FBS and 1\% penicillin-streptomycin before seeding MP-38 cells $\left(1.5 \times 10^{4}\right.$ cell per well $)$ on the surface of the CO-HA Gel or blank NP/CO-HA Gel composites. At pre-determined timepoints, cells were stained with LIVE/DEAD assay following the manufacturer's instruction and imaged by EVOS ${ }^{\circledR}$ FL Auto Cell Imaging System (Thermo Fisher Scientific, Waltham, MA, USA) via GFP, TexasRed, and Transmission channels. Cell number was quantified by Image J. Cell viability was calculated based on the equation below:

$$
\text { Cell viability }(\%)=\left(\frac{\text { Cell number }_{\text {Live }(G F P)}}{\text { Cell number }_{\text {Live }(\text { GFP })}+\text { Cell number }_{\text {Dead }(T x R e d)}}\right) \times 100 \%
$$

\subsection{Statistical Analysis}

All data was collected and presented as mean \pm S.D. (standard deviation). Statistical analysis was performed using Student's $t$-test with $p<0.05$ as the minimal level of significance. 


\section{Results and Discussion}

\subsection{Characteristics of NP}

As shown in Table 1, NP with (Cur NP) or without curcumin (BLK NP) was $161.9 \pm$ $5.1 \mathrm{~nm}$ and $156.6 \pm 1.5 \mathrm{~nm}$ in size with a narrow particle size distribution $(\mathrm{PDI}<0.1)$, respectively. BLK and Cur NP were negatively charged with a zeta potential around -26 to $-28 \mathrm{mV}$. Due to the abundant presence of negatively charged HA in the vitreous chamber, the negative surface charge of Cur NP was considered to be favorable, as it can avoid charge trapping and maintain NP mobility to facilitate drug delivery to the target posterior segments (e.g., choroid).

Table 1. Particle size, size distribution and surface charge of polymeric nanoparticles (NP) $(n=3)$.

\begin{tabular}{cccc}
\hline Sample & Size $(\mathbf{n m})$ & PDI & Zeta Potential (mV) \\
\hline Blank (BLK) NP & $161.9 \pm 5.1$ & $0.074 \pm 0.031$ & $-26.1 \pm 2.0$ \\
Lyophilized BLK NP & $159.7 \pm 2.2$ & $0.069 \pm 0.024$ & $-27.5 \pm 1.0$ \\
Curcumin (Cur) NP & $156.6 \pm 1.5$ & $0.056 \pm 0.027$ & $-27.9 \pm 1.2$ \\
Lyophilized Cur NP & $163.4 \pm 1.0$ & $0.070 \pm 0.021$ & $-31.2 \pm 0.2$ \\
\hline
\end{tabular}

In order to ensure long-term storage stability of Cur NP and to fabricate NP/CO-HA Gel composites, dry NP was obtained via lyophilization. During the lyophilization process, the pre-frozen step induced water crystal that can disrupt the stabilizer shell around NP, resulting in clustering during the reconstitution step [47]. Accordingly, various cryoprotectants (i.e., trehalose, mannitol, and sucrose) at different cryoprotectant to NP weight ratios were investigated. Among all the cryoprotectants studied, sucrose demonstrated superior cryoprotective effect against nanoparticle aggregation during the lyophilization process and hence was selected as the cryoprotectant. As shown in Table 1, NP remained similar particle size and zeta potential following the reconstitution process when sucrose was used at a NP/sucrose weight ratio of 25:1. Curcumin loading of the lyophilized Cur $\mathrm{NP}$ was $0.20 \pm 0.004 \%(w / w)(n=3)$. The reported $\mathrm{IC}_{50}$ of curcumin NP against cancer and metastatic cancer cells (e.g., pancreatic, ovarian, metastatic breast) was in the range of $10-15 \mu \mathrm{M}[48,49]$. Therefore, it is considered that our NP had sufficient curcumin loading. In addition, the value $\mathrm{IC}_{50}$ of Cur NP against MP-38 cells was about $19 \%$ lower than that of the first-line treatment dacarbazine group (data not shown). The morphology of lyophilized Cur NP was shown in Figure 1a. The NP showed a spherical shape with a homogenous size distribution (around $85.8 \pm 15.6 \mathrm{~nm}$ ). It was expected that the particle size observed via SEM was smaller than the hydrodynamic diameter determined via DLS.

(a)

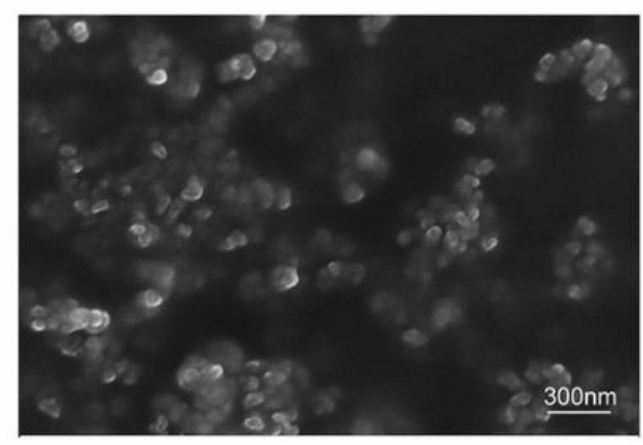

(b)

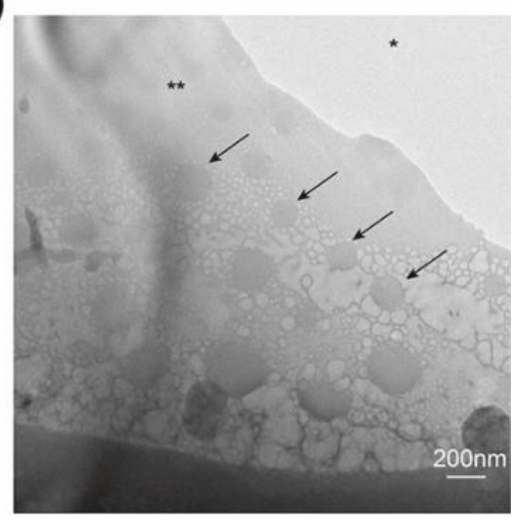

Figure 1. (a) Scanning electron microscope (SEM) image of curcumin nanoparticles (Cur NP). (b) Representative cryogenic transmission electron microscope (Cryo-TEM) image of the Cur NP/hydrogel composite. Arrows indicate Cur NP; ${ }^{*}$ TEM cooper grid, ${ }^{* *}$ Gel composite. 


\subsection{Characteristics of CO-HA Gels}

Two 8-arm PEG's were used to prepare our hydrogel Gel 1 (MW: $20 \mathrm{kDa}$ ) and Gel 2 (MW: $40 \mathrm{kDa}$ ), respectively. It can be seen in Figure 2a that the CO-HA Gel mixture was in a liquid state at room temperature. Following incubation at $37^{\circ} \mathrm{C}$ (body temperature), the mixture quickly crosslinked between succinimidyl groups of 8-arm PEG and primary amine groups of collagen to form a transparent semisolid gel (Figure 2b). The developed CO-HA Gel with good luminous transmittance $(>98 \%)$ that was close to water (Figure S1a). To fabricate NP-loaded hydrogel composite, NP was mixed into the CO-HA Gel mixture prior to the gelation process. As shown in Figure 1b, NP with a spherical shape was homogeneously distributed in the CO-HA Gel composite matrix. The optical properties of NP incorporated CO-HA Gel composites was also studied (supplementary materials). The presence of a high dose NP in the NP/Gel composites resulted in a decrease in the luminous transmittance compared to the control (DI water) and CO-HA Gel group (Figure S1a). The luminous transmittance of the Cur NP/Gel composite between 380 and $480 \mathrm{~nm}$ was decreased, as curcumin has light absorbance at around $430 \mathrm{~nm}$, but it was higher than that of the BLK NP/Gel composite when the wavelength was above $500 \mathrm{~nm}$. Whether the presence of yellowish curcumin would potentially impair the visual process will be further investigated and discussed following an in vivo anti-UM dose optimization study in the future. Nevertheless, the Gel and NP/Gel composites studied can maintain good transparence as shown in Figure S1b.

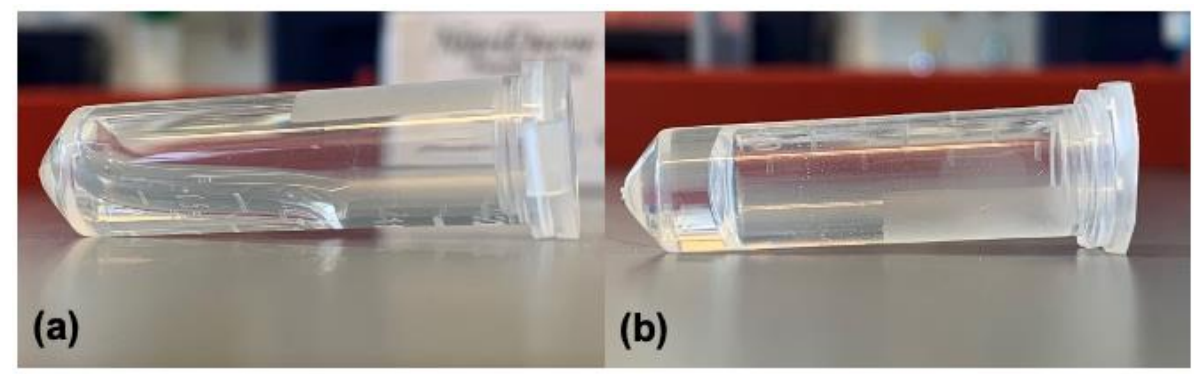

Figure 2. Representative photos of the blank hydrogel mixture at room temperature (a) and after incubation at $37^{\circ} \mathrm{C}(\mathbf{b})$.

\subsubsection{Rheological Properties}

The gelling time of blank CO-HA Gels was determined using a time sweep at $37^{\circ} \mathrm{C}$. Both CO-HA Gel 1 and Gel 2 showed a short gelling time around or below $1 \mathrm{~min}$ at $37^{\circ} \mathrm{C}$. This confirmed that the developed CO-HA Gel can quickly transform from a liquid state to a semisolid gel state at body temperature. The CO-HA Gel 1 with a lower MW PEG had a shorter gelling time $(32.37 \pm 3.44 \mathrm{~s})$ than that $(58.66 \pm 9.33 \mathrm{~s})$ of the CO-HA Gel 2 with a higher MW PEG (Figure 3a,b). The same amount of collagen can crosslink with low MW PEG with a higher number of reactive groups in shorter duration [26]. The presence of Cur NP resulted in a slight increase in gelling time, but the impact was not significant. The NP/CO-HA Gel 1 and NP/CO-HA Gel 2 composites had a gelling time of $40.39 \pm 9.21$ and $63.64 \pm 5.21$ s, respectively (Figure 3b). Overall, Gel 1 and NP/CO-HA Gel 1 composite had a significant shorter gelling time compared with Gel 2 and NP/CO-HA Gel 2 composite $(p<0.05)$, respectively.

The mechanical properties of CO-HA Gels and NP/Gel composites were studied using unconfined compression testing. All the testing samples were evaluated in a LVR ( $0.5 \%$ to $20 \%$ strain). The average storage moduli of Gel 1 and Gel 2 determined based on the oscillation frequency method were $182.26 \pm 3.93$ and $166.84 \pm 20.26 \mathrm{~Pa}(p>0.05)$, respectively (Figure $4 a, b)$. The presence of NP had a stronger effect on the storage modulus $(69.54 \pm 10.10 \mathrm{~Pa})$ of the NP/Gel 2 composite, compared to that $(148.96 \pm 19.15 \mathrm{~Pa})$ of the NP/Gel 1 composite. The crosslinking density of Gel or its NP/Gel composite was calculated based on their storage moduli. Gel 2 had a slightly lower crosslinking density $\left(0.064 \pm 0.008 \mathrm{~mol} / \mathrm{cm}^{3}\right)$ than Gel $1\left(0.071 \pm 0.002 \mathrm{~mol} / \mathrm{cm}^{3}\right)$, which can be explained 
by the less functional succinimidyl groups present in the higher MW PEG. Overall, the presence of NP resulted in a decrease in crosslinking density for both NP/Gel 1 and $\mathrm{NP} / \mathrm{Gel} 2$ composites $\left(0.058 \pm 0.007 \mathrm{~mol} / \mathrm{cm}^{3}\right.$ and $0.027 \pm 0.004 \mathrm{~mol} / \mathrm{cm}^{3}$, respectively) The presence of NP in the Gel mesh matrix may increase distance between polymer chains, thus decreasing the storage modulus [50]. The Gel 2 composite with a higher MW had higher collagen mobility and less reactive groups [26]. The presence of NP may further inhibit crosslinking, resulting in significant decrease in the storage modulus of the Gel 2 composite.

(a)
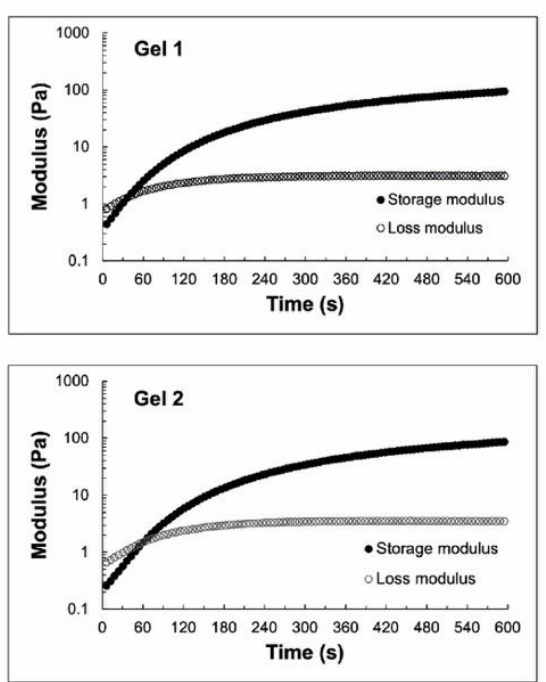
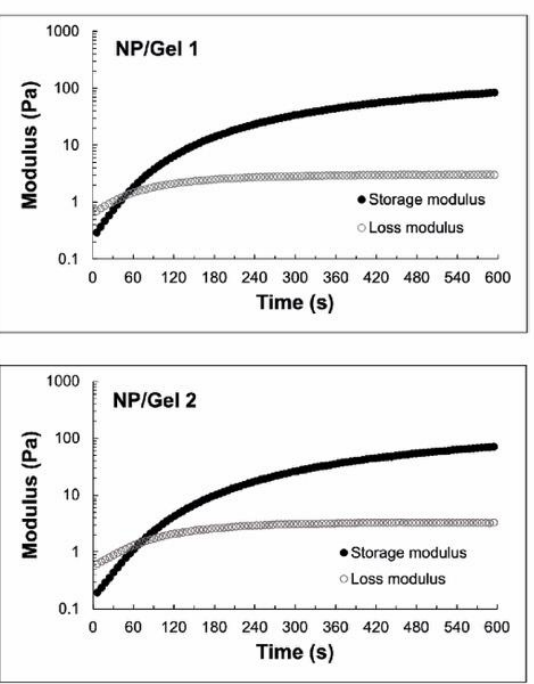

(b)

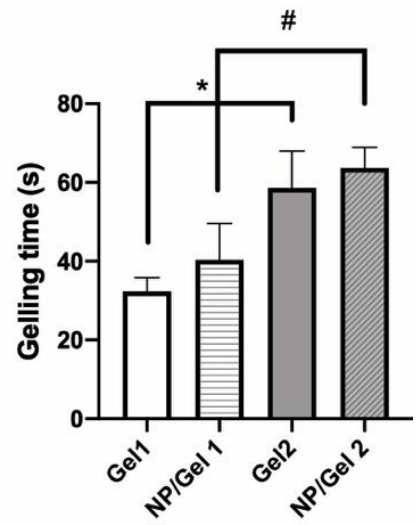

Figure 3. (a) Rheological properties of Gel 1, Gel 2 and nanoparticles (NP)/Gel composites obtained via time sweep with $1 \mathrm{~Hz}$ frequency and $5 \%$ strain at $37^{\circ} \mathrm{C}(n=3)$. (b) Gelling time of the different Gel and its NP/Gel composite $(n=3)$. Statistical analysis comparing between Gels or NP/Gel composites, ${ }^{*}, \# p<0.05$.

(a)
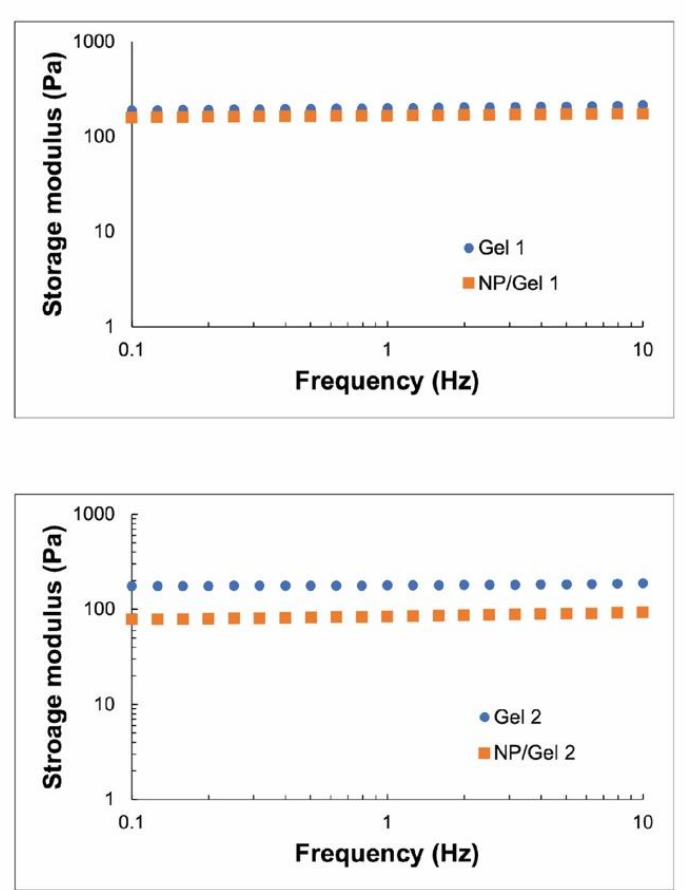

(b)

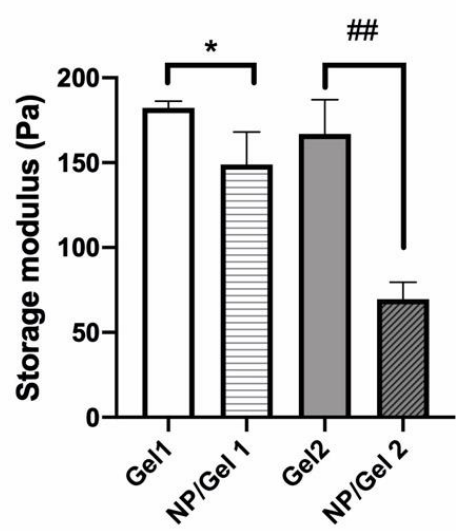

Figure 4. (a) Unconfined compression measurements of Gels and nanoparticle (NP)/Gel composites with oscillation frequency ranging from 0.1 to $10 \mathrm{~Hz}$ at $5 \%$ strain at $37^{\circ} \mathrm{C}(n=3)$. (b) The storage moduli of the Gels and their respective $\mathrm{NP} / \mathrm{Gel}$ composites obtained at $5 \%$ strain and $1 \mathrm{~Hz}$ frequency $(n=3)$. Statistical analysis comparing between Gels and their respective NP/Gel composites, ${ }^{*} p<0.05$, \#\# $p<0.01$. 
Overall, storage moduli of the CO-HA Gels and NP/CO-HA Gel composites were in a range of 55 to $200 \mathrm{~Pa}$, which was comparable to many soft tissues including the human vitreous body (0.24-14.5 Pa) [51] and similar to the reported hydrogels studied as an artificial vitreous body [52]. In addition, our CO-HA Gel system with high viscosity $\left(22.6 \pm 2.73 \mathrm{~Pa} \cdot \mathrm{s}\right.$ and $10.9 \pm 1.59 \mathrm{~Pa} \cdot \mathrm{s}$ at $37^{\circ} \mathrm{C}$ for NP/CO-HA Gel 1 and Gel 2, respectively) can increase the viscoelasticity of the vitreous body is unlikely cause turbulent flow in the human vitreous humor and [51,53], thus reducing the risk of retinal re-detachment. This indicated that the developed in situ gelling hydrogels and NP/hydrogel composites may be well tolerated in these soft tissues. In vivo compatibility will be studied using an animal model in the future.

\subsubsection{Internal Structure and Morphology of CO-HA Gels}

The internal structure of CO-HA Gel 1 and Gel 2 was characterized using cryo-SEM. As shown in Figure 5, Gel 2 showed a slightly smaller mesh area $(70.66 \pm 3.56 \%)$ and median mesh diameter $\left(D_{50}: 7.67 \mu \mathrm{m}\right)$ than Gel 1 (mesh area: $73.70 \pm 2.93 \%$ and $D_{50}: 9.89 \mu \mathrm{m}$, Table 2). In addition, Gel 2 had a higher mesh size span value (1.89) than Gel 1 (span value: 1.46), indicating that the meshes of Gel 2 had a wider mesh size distribution. It has been reported that the component and composition of a hydrogel and crosslinking density can influence hydrogel mesh size [28]. Considering that the difference in crosslinking density of Gel 1 and Gel 2 was not significant ( $p>0.05$ ), PEG MW appeared to play a significant role in the mesh size distribution. The high MW PEG with a longer polymer chain may lead to the formation of interpenetrating polymer networks and hence smaller meshes.
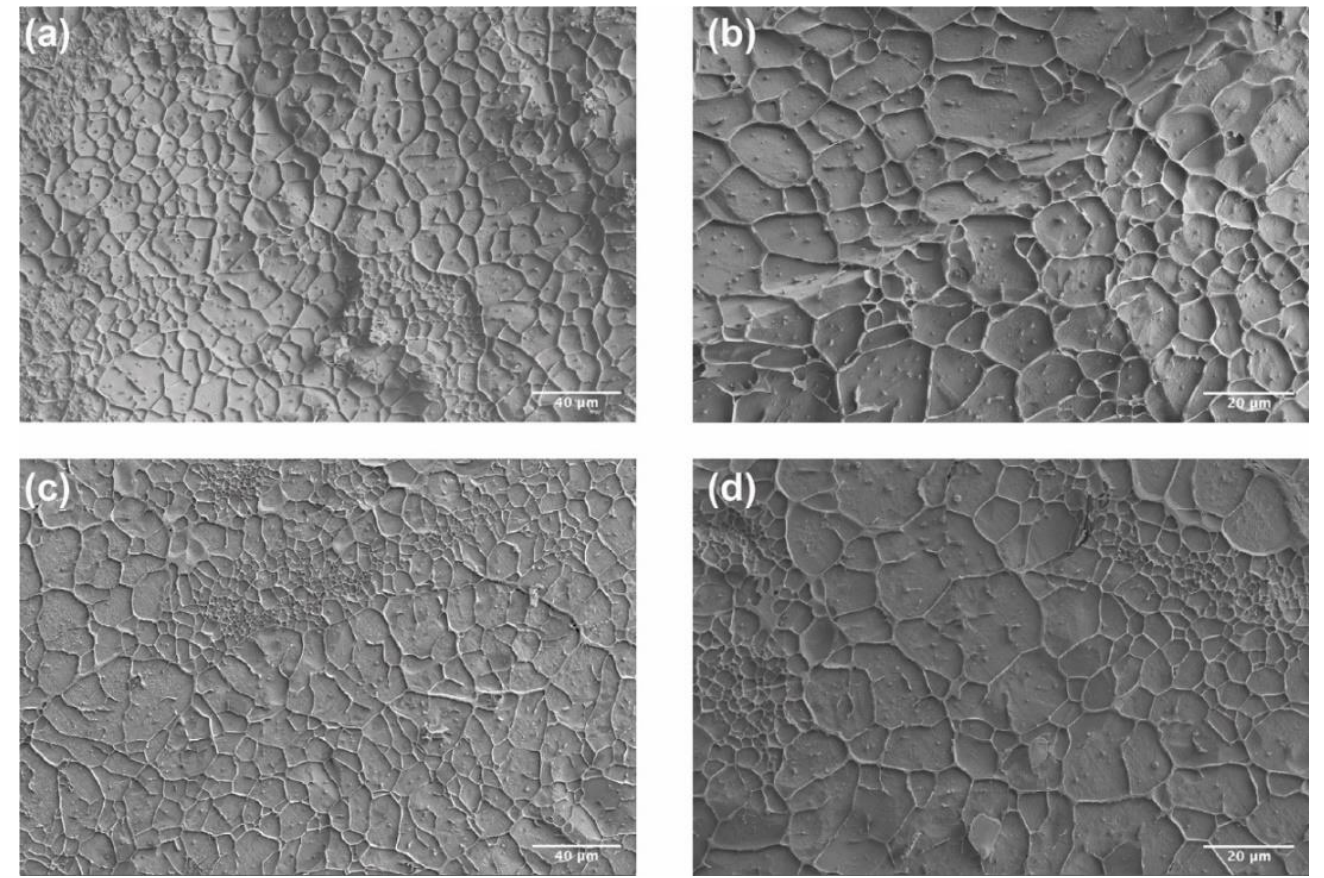

Figure 5. Cryo-SEM images of Gel 1 (20 kDa PEG) (a,b) and Gel 2 (40 kDa PEG) (c,d). Scale bar: (a,c) $40 \mu \mathrm{m} ;(\mathbf{b}, \mathbf{d}) 20 \mu \mathrm{m}$.

Table 2. Mesh size of Gel 1 and Gel 2.

\begin{tabular}{|c|c|c|c|c|c|}
\hline \multirow{2}{*}{ Gel } & \multicolumn{4}{|c|}{ Mesh Diameter $(\mu \mathrm{m})$} & \multirow{2}{*}{$\begin{array}{c}\text { Mesh Area } \\
\text { (\%) }\end{array}$} \\
\hline & $D_{10}$ & $D_{50}$ & $D_{90}$ & Span & \\
\hline Gel 1 & 5.70 & 9.89 & 20.13 & 1.46 & $73.70 \pm 2.93$ \\
\hline Gel 2 & 3.84 & 7.67 & 18.36 & 1.89 & $70.66 \pm 3.56$ \\
\hline
\end{tabular}




\subsubsection{Swelling Property and Equilibrium Water Content}

The swelling property and EWC of CO-HA Gels were also studied. Overall, our CO-HA Gels showed relatively low swelling (below 10\%). Gel 1 with a higher crosslinking density exhibited less swelling $(8.29 \pm 0.37 \%)$ than Gel $2(13.84 \pm 3.61 \%)$ with a lower crosslinking density (Figure 6). The swelling of hydrogels inevitably causes decrease in mechanical strength, morphology changes, and bulk degradation [54,55]. In addition, swollen hydrogel may cause not only slippage from the implantation or injection site but also tissue compression [56]. Therefore, our CO-HA gel system with low swelling in the aqueous environment is considered desirable in achieving prolonged drug release while maintaining good compatibility with surrounding tissues. The calculated EWC of CO-HA Gel 1 and Gel 2 was $96 \pm 0.12 \%$ and $97 \pm 0.3 \%$, respectively, which were very similar to that of HA hydrogel reported previously (EWC ranging from 60-99\%) [57-59]. The water content of the human body is around $60 \%$ [60] and that of the eye vitreous body is around 98\% [61]. Accordingly, our CO-HA Gels with similar fluid content to living tissues may have excellent tissue compatibility.
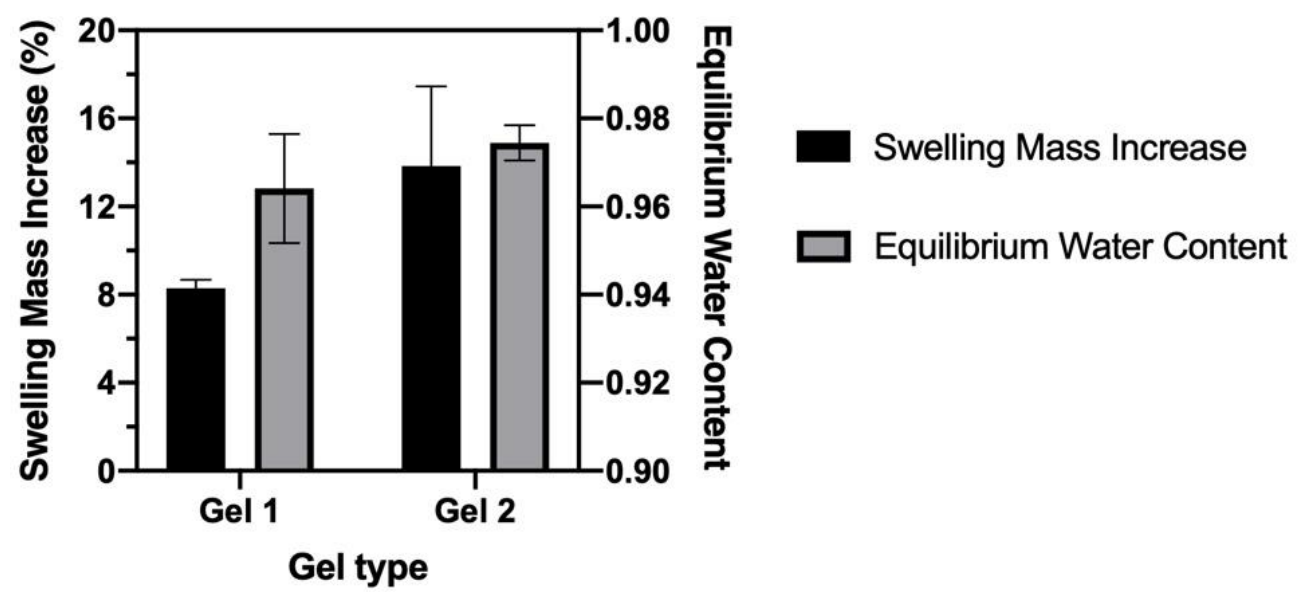

Figure 6. Swelling mass increase and equilibrium water content of CO-HA Gels $(n=3)$.

\subsection{In Vitro Degradation of CO-HA Gels}

In vitro degradation behavior of CO-HA Gel 1 and Gel 2 was studied in saline at $37^{\circ} \mathrm{C}$. CO-HA Gel was formed through ester linkers between PEG and collagen II and the ester linkers are susceptible to hydrolytic degradation. Therefore, the non-crosslinked free amine groups determined using the TNBS assay can indirectly reflect the crosslinking degree between PEG and collagen when compared with collagen alone [46,62]. The changes in free amine groups of Gel 1 and Gel 2 were monitored during a 4-week degradation study. The initial free amine group percentage of Gel 1 and Gel 2 without degradation was $3.9 \pm 1.02 \%$ and $24.4 \pm 2.45 \%$, respectively. The lower amount of free amine groups in Gel 1 than Gel 2 confirmed the higher crosslinking degree of Gel 1 than Gel 2, which was consistent with the crosslinking density results described in Section 3.2.1. As shown in Figure 7, the percentage of free amine groups of both Gels gradually increased with the degradation of the hydrogels over 4 weeks. Gel 1 and Gel 2 had $47.6 \pm 1.02 \%$ and $68.0 \pm 3.21 \%$ free amine groups by day 28 , respectively. There was no obvious gel structure change observed for both Gels. These results indicated that slow degradation behavior of the developed in situ CO-HA Gels, which can be used to achieve sustained payload release. 


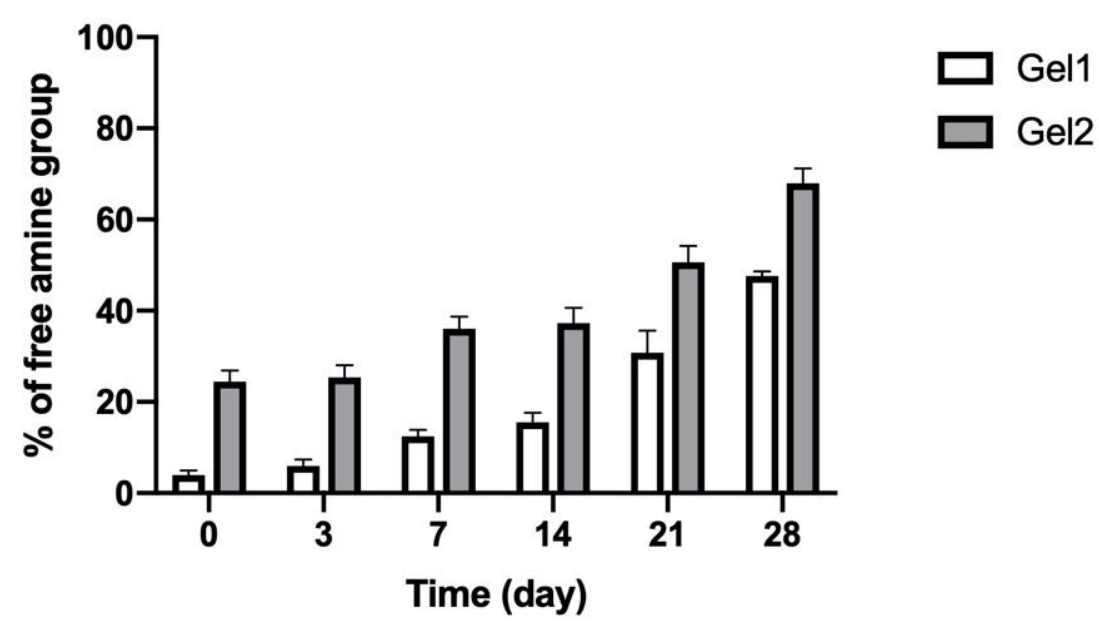

Figure 7. Percentage (\%) of free amine groups in CO-HA Gels during in vitro degradation testing in saline at $37^{\circ} \mathrm{C}$ over four weeks $(n=3)$.

Collagenase and hyaluronidase are the main enzymes exist in the human body that can degrade collagen and hyaluronic acid, respectively. Therefore, in vitro degradation of CO-HA Gel was also studied in the presence of collagenase $(75 \mathrm{U} / \mathrm{mL})$ and hyaluronidase $(16.7 \mathrm{U} / \mathrm{mL})$. The high concentration collagenase can completely degrade Gel 1 and Gel 2 in 7 and 3 days, respectively. Under the neutral environments, the activity of hyaluronidase was largely decreased [63]. As a result, no obvious degradation was observed for Gel 1 and Gel 2 following a 7-day incubation of high concentration hyaluronidase (data now shown). It is worth mentioning that both collagenase and hyaluronidase are not abundant in the human vitreous humor $[64,65]$. Accordingly, the hydrolytic degradation may be the main degradation pathway of our CO-HA Gel. The degradation of CO-HA Gel in the vitreous humor will be studied using an animal model in the future.

\subsection{In Vitro Release Characteristics of Cur NP/CO-HA Gel Composites}

In vitro release characteristics of the Cur NP/Gel composites were studied in the presence of stabilizers including $10 \%(w / v)$ Tween $80,0.1 \%(w / v)$ NAC, and $0.01 \%(w / v)$ BHT to minimize curcumin degradation during long-term release studies $[66,67]$. As shown in Figure 8a, curcumin slowly released from the Cur NP/Gel 1 composite and about $55 \%$ curcumin was released over four weeks, whereas the Cur NP/Gel 2 composite had a relatively higher curcumin release in the first two days, which may be due to higher swelling of Gel 2 and hence faster payload diffusion and higher initial curcumin release. With respect to the Cur NP/Gel 2 composite, curcumin release was slowed down after day 5 and reached a plateau in 10 days. The cumulative curcumin released was around $43 \%$ by the end of four weeks. Overall, the NP/Gel 1 composite showed better sustained curcumin release behavior. This may be attributed to its higher portion of large meshes through which payload can transport to the release medium (Table 2). In order to demonstrate whether intact NP can be released from the composite, release samples collected were imaged via Cryo-TEM. As shown in Figure 8c, spherical Cur NP was observed in the day-5 release samples, and the released Cur NP showed a similar particle size compared to that of the control group (NP suspended in water) (Figure 8d). These results demonstrated that intact Cur NP can be sustained released from our CO-HA Gels, which may lead to better transport of curcumin in the vitreous humor to reach its target posterior site (i.e., choroid). 
(a)

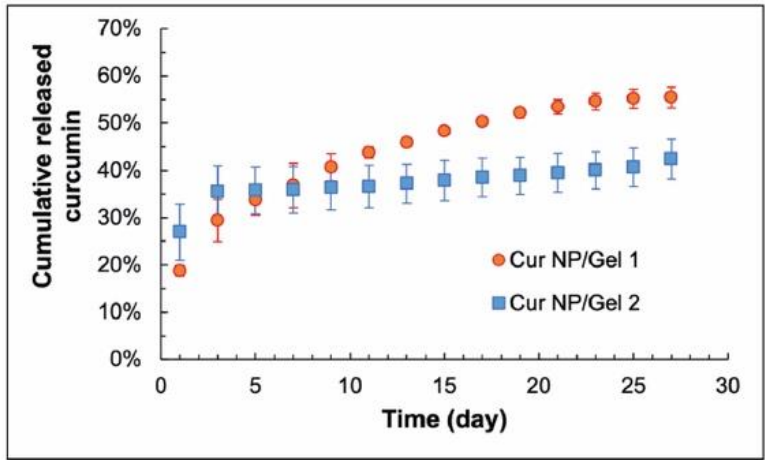

(c)

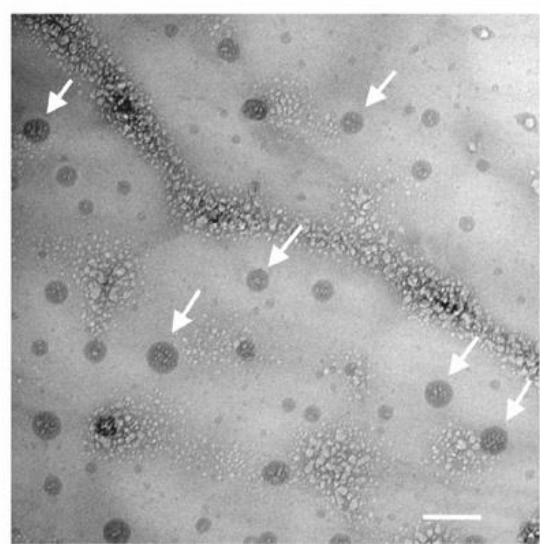

(b)

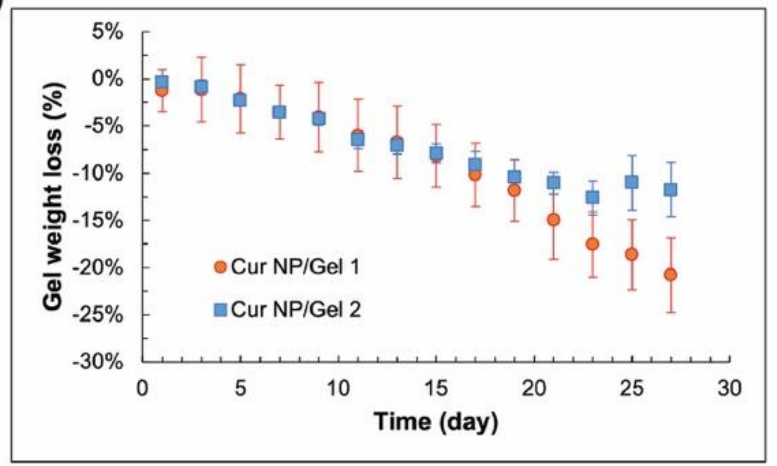

(d)

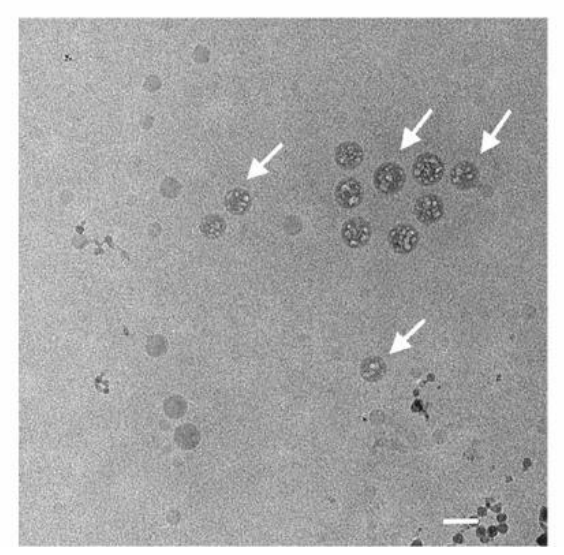

Figure 8. (a) In vitro curcumin release profiles and (b) weight loss profiles of curcumin nanoparticles (Cur NP)/Gel 1 and Cur NP/Gel 2 composites in saline containing 10\% (w/v) Tween 80, 0.1\% (w/v) N-acetylcysteine (NAC), and 0.01\% ( $w / v)$ butylated hydroxytoluene (BHT) at $37^{\circ} \mathrm{C}(n=3)$. (c) Cryo-TEM image of the representative day-5 release sample of Cur NP/Gel 1 composite. (d) Cryo-TEM image of Cur NP dispersed in water as a control. Arrows indicate NP. Scale bar: $100 \mathrm{~nm}$.

The weight loss of the Cur NP/Gel composites was also monitored during the release study. It can be seen in Figure $8 b$ that both NP/Gel composites had a similar weight loss over the first 20 days. The weight loss of the Cur NP/Gel 2 composite reached a plateau at around day 23, whereas a gradual weight loss was observed for the Cur NP/Gel 1 composite over four weeks. This was consistent with the sustained curcumin release from the Cur NP/Gel 1 composite. The Cur NP/Gel 1 composite with a better sustained curcumin release profile was selected for the anti-UM effect study.

\subsection{In Vitro Anti-UM Effect of Cur CO-HA Gel Composites}

A "proof-of-concept" short-term in vitro cell study for 3 days was conducted due to the challenges in culturing cells for prolonged duration (e.g., 30 days). Cur NP amount loaded into Gel 1 was determined based on curcumin $\mathrm{IC}_{50}$ and release behavior from the Cur NP/Gel composite (Figure 8a). Compared to the Cur/Gel 1 (cell viability: $107.3 \pm 2.57 \%$ ) and BLK NP/Gel 1 groups (cell viability: $93.8 \pm 8.32 \%$ ), the developed Cur NP/Gel 1 showed significantly decreased cell viability $(52.7 \pm 2.86 \%)(p<0.01)$ (Figure 9$)$. The result demonstrated that sustained curcumin release from the Cur NP/Gel 1 composite successfully inhibited UM cell growth. The poor anti-UM efficiency of the Cur/Gel 1 group may be resulted from the poorly water solubility and instability of curcumin in the aqueous environment $(\mathrm{pH}>7)$ [68], thus the lack of sustained therapeutic effect [69]. The Cur NP group (NP alone) showed significantly lower cell viability (29.8 $\pm 9.04 \%)$ compared to the Cur NP/Gel 1 composite group, as the Cur NP amount was the same 
as that loaded in Cur NP/Gel 1 composite for a 30-day treatment instead of cur amount released in the first 3 days. It has been reported that curcumin can down regulate HIF- $1 \alpha$ pathway [68]. A significant decrease in HIF-1 $\alpha$ mRNA expression level of MP-38 cells following the treatment of Cur NP for $24 \mathrm{~h}$ under hypoxia conditions was observed via RT-qPCR $(p<0.05)$ (data not shown). This result suggested that downregulation of HIF- $1 \alpha$ pathway could be one of the reasons for anti-UM effect of Cur NP.

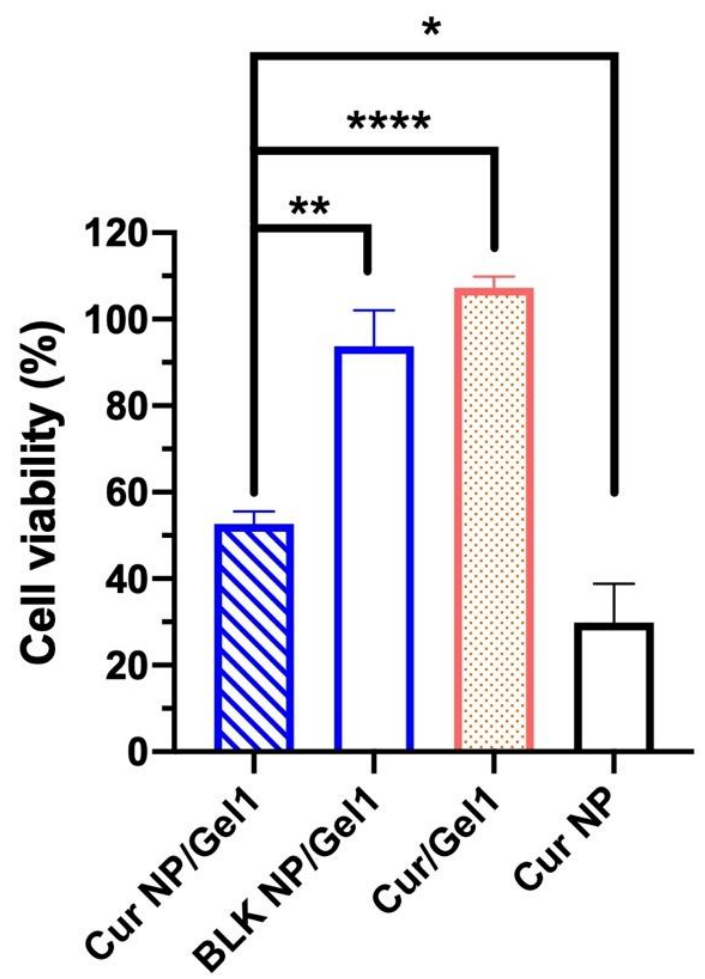

Figure 9. Cell viability of MP-38 cells following the treatment with curcumin nanoparticles (Cur NP)/Gel 1 composite, blank (BLK) NP/Gel 1 composite, Cur/Gel 1 composite and Cur NP for 3 days $(n=3)$. Statistical analysis comparing the Cur NP/Gel 1 composite with the control groups; * $p<0.05$, ** $p<0.01, * * * * 00.0001$.

As shown in Figure 10, the MP-38 cells grown on the surface of the Gel 1 and BLK $\mathrm{NP} /$ Gel 1 composites had above $80 \%$ live cells during a period of 7 days, indicating low cytotoxicity. UM cells grown on culture plate was studied as a control and showed a significantly high live cell numbers compared to the Gel groups $(p<0.05)$ as culture plate has more even surface compared to hydrogel surfaces. It can be seen in Figure 10a that the cells grown on Gel 1 and BLK NP/Gel 1 composite had very similar morphology and live cell numbers (\%), suggesting that the incorporated our PLGA NP did not decrease Gel's cell compatibility. The low cytotoxicity of the CO-HA Gel 1 and its composite can be attributed to the excellent biocompatibility of the hydrogel components (i.e., collagen, HA). This result confirmed that the excellent anti-UM effect showed in Figure 9 was attributed to sustained Cur release from the Cur NP/Gel composite. Despite that the hydrogel components (i.e., collagen and hyaluronic acid) have excellent biocompatibility and good ocular safety of curcumin has been previously demonstrated using cell lines such as human retinal pigmented epithelial (D407) cells [70], 661W and ARPE-19 retinal cells [71], the ocular safety of the developed Cur NP/Gel composite needs to be investigated using an animal model in the future. 
(a) Day 2

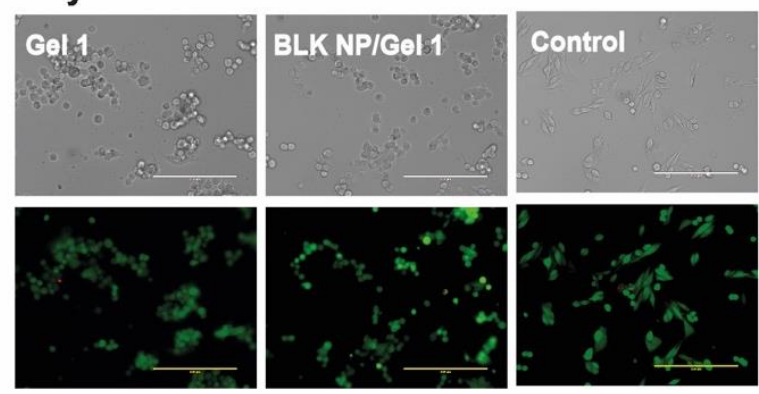

Day 4
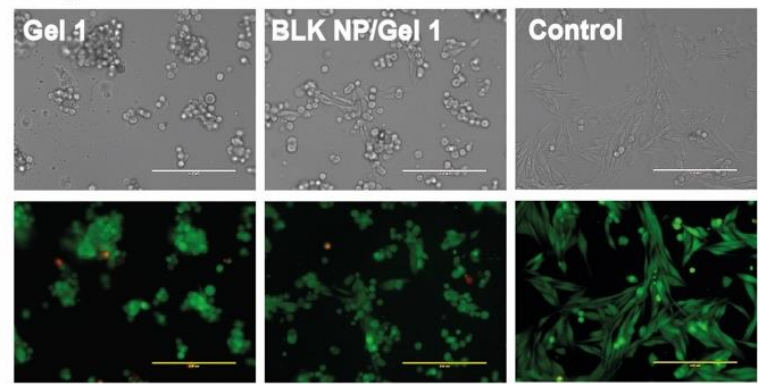

\section{Day 7}
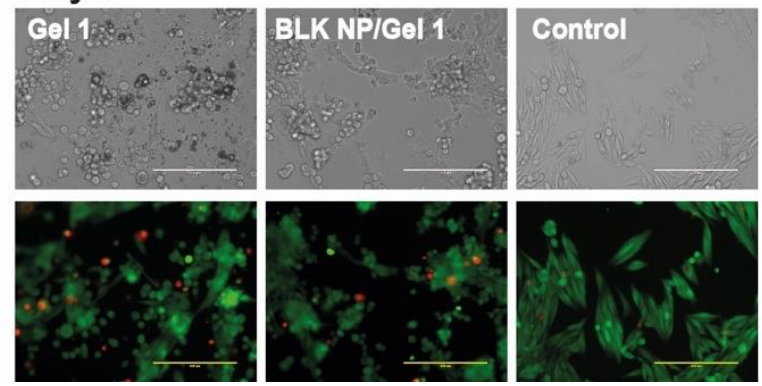

(b)

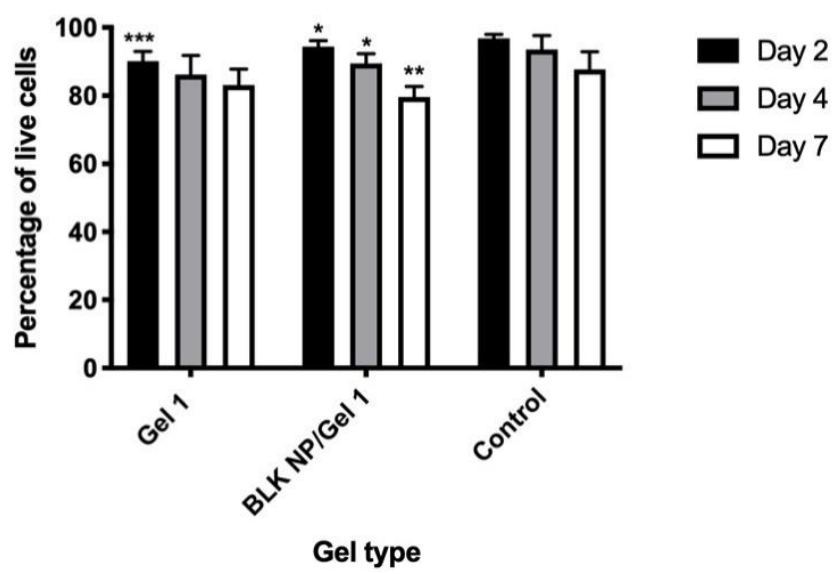

Figure 10. (a) Bright field and fluorescence images of MP-38 cells grown on CO-HA Gel 1 and blank NP (BLK NP)/Gel 1 composites at day 2, day 4, and day 7. MP-38 cells cultured in a 96well culture plate were studied as a control. Scale bar: $200 \mu \mathrm{m}$. The MP-38 Cells were labeled with the LIVE/DEAD assay. Green and red fluorescence indicate live and dead cells, respectively. (b) Quantification results of live cell (\%) of testing group: Gel 1, BLK NP/Gel 1 composites and the control $(n=3)$. Statistical analysis comparing experimental groups to the control group on the same day; ${ }^{*} p<0.05,{ }^{* *} p<0.01,{ }^{* * *} p<0.001$. 


\section{Conclusions}

The present research developed a long-acting, injectable, in situ gelling hydrogel delivery platform inspired by the nature components of the vitreous body. The in situ gelling hydrogel composed of nature occurring polymers collagen and hyaluronic acid demonstrated excellent biocompatibility and can gel within minutes at the body temperature. In addition, the in situ gelling hydrogel with low swelling and soft storage modulus degraded slowly and was capable of sustained release payload over four weeks. More importantly, the curcumin nanoparticle/in situ hydrogel composite demonstrated excellent anti-UM effect in a short-term anti-UM effect study. These results demonstrated the great potential of the developed nanoparticle/in situ hydrogel composite for sustained treatment of uveal melanoma in the posterior chamber. The biodistribution in ocular tissues (e.g., choroid and retina) and anti-UM effect and safety (e.g., tissue compatibility and intraocular pressure) of the developed Cur NP/Gel composite need to be further studied using an animal model.

Supplementary Materials: The following are available online at https:/ / www.mdpi.com/article / 10.3390/pharmaceutics13091335/s1, Figure S1: (a) Optical transmittance spectra and (b) photo of CO-HA Gel 1 and NP/Gel 1 composites in a 96-well plate with a $125 \mu \mathrm{m}$ sample thickness. Water was studied as a control. References [72,73].

Author Contributions: Conceptualization, J.S. and L.X.; Methodology, L.X. and J.S.; Software, L.X.; Validation, L.X. and W.Y.; Formal Analysis, L.X. and W.Y.; Investigation, L.X., W.Y. and K.I.; Resources, J.S.; Data Curation, L.X.; Writing — Original Draft Preparation, L.X.; Writing-Review \& Editing, L.X., W.Y., and J.S.; Visualization, L.X. and J.S.; Supervision, J.S.; Project Administration, J.S.; Funding Acquisition, J.S. All authors have read and agreed to the published version of the manuscript.

Funding: This research was funded fully by the Rhode Island Institutional Development Award (IDeA) Network for Biomedical Research Excellence from the National Institute of General Medical Sciences of the National Institutes of Health under grant number P20GM103430.

Institutional Review Board Statement: Not applicable.

Informed Consent Statement: Not applicable.

Data Availability Statement: Data sharing not applicable. No new data were created or analyzed in this study. Data sharing is not applicable to this article.

Acknowledgments: We would like to thank Irene Andreu for assisting with the SEM, Cryo-SEM, and Cryo-SEM studies and Gabrielle Rozumek for her assistance with hydrogel characterization.

Conflicts of Interest: The authors declare no conflict of interest.

\section{References}

1. Bedikian, A.Y. Metastatic uveal melanoma therapy: Current options. Int. Ophthalmol. Clin. 2006, 46, 151-166. [CrossRef] [PubMed]

2. Kaliki, S.; Shields, C. Uveal melanoma: Relatively rare but deadly cancer. Eye 2017, 31, 241-257. [CrossRef] [PubMed]

3. Kivelä, T.; Puusaari, I.; Damato, B. Transscleral resection versus iodine brachytherapy for choroidal malignant melanomas 6 millimeters or more in thickness: A matched case-control study. Ophthalmology 2003, 110, 2235-2244. [CrossRef]

4. Puusaari, I.; Damato, B.; Kivelä, T. Transscleral local resection versus iodine brachytherapy for uveal melanomas that are large because of tumour height. Graefe's Arch. Clin. Exp. Ophthalmol. 2007, 245, 522-533. [CrossRef]

5. Bechrakis, N.E.; Petousis, V.; Willerding, G.; Krause, L.; Wachtlin, J.; Stroux, A.; Foerster, M.H. Ten-year results of transscleral resection of large uveal melanomas: Local tumour control and metastatic rate. Br. J. Ophthalmol. 2010, 94, 460-466. [CrossRef] [PubMed]

6. Woodman, S.E. Metastatic uveal melanoma: Biology and emerging treatments. Cancer J. 2012, 18, 148-152. [CrossRef]

7. Kaur, J.; Malik, M.A.; Gulati, R.; Azad, S.V.; Goswami, S. Genetic determinants of uveal melanoma. Tumour. Biol. 2014, 35, 11711-11717. [CrossRef]

8. Carvajal, R.D.; Schwartz, G.K.; Tezel, T.; Marr, B.; Francis, J.H.; Nathan, P.D. Metastatic disease from uveal melanoma: Treatment options and future prospects. Br. J. Ophthalmol. 2017, 101, 38-44. [CrossRef]

9. Onken, M.D.; Li, J.; Cooper, J.A. Uveal melanoma cells utilize a novel route for transendothelial migration. PLoS ONE 2014, 9, e115472. [CrossRef] 
10. Amirouchene-Angelozzi, N.; Schoumacher, M.; Stern, M.H.; Cassoux, N.; Desjardins, L.; Piperno-Neumann, S.; Lantz, O.; Roman-Roman, S. Upcoming translational challenges for uveal melanoma. Br. J. Cancer 2015, 113, 1746. [CrossRef]

11. Violanti, S.S.; Bononi, I.; Gallenga, C.E.; Martini, F.; Tognon, M.; Perri, P. New insights into molecular oncogenesis and therapy of uveal melanoma. Cancers 2019, 11, 694. [CrossRef]

12. Souto, E.; Zielinska, A.; Luis, M.; Carbone, C.; Martins-Gomes, C.; Souto, S.; Silva, A. Uveal melanoma: Physiopathology and new in situ-specific therapies. Cancer Chemother. Pharmacol. 2019, 84, 15-32. [CrossRef] [PubMed]

13. Ortega, M.A.; Fraile-Martínez, O.; García-Honduvilla, N.; Coca, S.; Álvarez-Mon, M.; Buján, J.; Teus, M.A. Update on uveal melanoma: Translational research from biology to clinical practice. Int. J. Oncol. 2020, 57, 1262-1279. [CrossRef] [PubMed]

14. Voropaev, H.; Gimmelshein Vatkin, M.; Shneor, D.; Luski, S.; Honigman, A.; Frenkel, S. Infectious Knockdown of CREB and HIF-1 for the Treatment of Metastatic Uveal Melanoma. Cancers 2019, 11, 1056. [CrossRef] [PubMed]

15. el Filali, M.; Missotten, G.S.; Maat, W.; Ly, L.V.; Luyten, G.P.; van der Velden, P.A.; Jager, M.J. Regulation of VEGF-A in uveal melanoma. Investig. Ophthalmol. Vis. Sci 2010, 51, 2329-2337. [CrossRef]

16. Xie, L.; Yang, Y.; Shen, J. Efficient inhibition of uveal melanoma via ternary siRNA complexes. Int. J. Pharm. 2020, 573, 118894. [CrossRef]

17. Dong, L.; You, S.; Zhang, Q.; Osuka, S.; Devi, N.S.; Kaluz, S.; Ferguson, J.H.; Yang, H.; Chen, G.; Wang, B. Arylsulfonamide 64B inhibits hypoxia/HIF-induced expression of c-Met and CXCR4 and reduces primary tumor growth and metastasis of uveal melanoma. Clin. Cancer Res. 2019, 25, 2206-2218. [CrossRef]

18. Asnaghi, L.; Lin, M.H.; Lim, K.S.; Lim, K.J.; Tripathy, A.; Wendeborn, M.; Merbs, S.L.; Handa, J.T.; Sodhi, A.; Bar, E.E. Hypoxia promotes uveal melanoma invasion through enhanced Notch and MAPK activation. PLoS ONE 2014, 9, e105372. [CrossRef]

19. Kaur, I.P.; Kakkar, S. Nanotherapy for posterior eye diseases. J. Control. Release 2014, 193, 100-112. [CrossRef]

20. Wang, B.; Tang, Y.; Oh, Y.; Lamb, N.W.; Xia, S.; Ding, Z.; Chen, B.; Suarez, M.J.; Meng, T.; Kulkarni, V.; et al. Controlled release of dexamethasone sodium phosphate with biodegradable nanoparticles for preventing experimental corneal neovascularization. Nanomedicine 2019, 17, 119-123. [CrossRef]

21. Elsaid, N.; Jackson, T.L.; Elsaid, Z.; Alqathama, A.; Somavarapu, S. PLGA microparticles entrapping chitosan-based nanoparticles for the ocular delivery of ranibizumab. Mol. Pharm. 2016, 13, 2923-2940. [CrossRef]

22. Kompella, U.B.; Amrite, A.C.; Pacha Ravi, R.; Durazo, S.A. Nanomedicines for back of the eye drug delivery, gene delivery, and imaging. Prog. Retin. Eye Res. 2013, 36, 172-198. [CrossRef] [PubMed]

23. Agrahari, V.; Agrahari, V.; Mandal, A.; Pal, D.; Mitra, A.K. How are we improving the delivery to back of the eye? Advances and challenges of novel therapeutic approaches. Expert Opin. Drug Deliv. 2017, 14, 1145-1162. [CrossRef] [PubMed]

24. Turturro, S.B.; Guthrie, M.J.; Appel, A.A.; Drapala, P.W.; Brey, E.M.; Perez-Luna, V.H.; Mieler, W.F.; Kang-Mieler, J.J. The effects of cross-linked thermo-responsive PNIPAAm-based hydrogel injection on retinal function. Biomaterials 2011, 32, 3620-3626. [CrossRef] [PubMed]

25. Xie, B.; Jin, L.; Luo, Z.; Yu, J.; Shi, S.; Zhang, Z.; Shen, M.; Chen, H.; Li, X.; Song, Z. An injectable thermosensitive polymeric hydrogel for sustained release of Avastin(R) to treat posterior segment disease. Int. J. Pharm. 2015, 490, 375-383. [CrossRef] [PubMed]

26. Sargeant, T.D.; Desai, A.P.; Banerjee, S.; Agawu, A.; Stopek, J.B. An in situ forming collagen-PEG hydrogel for tissue regeneration. Acta Biomater. 2012, 8, 124-132. [CrossRef]

27. Zou, L.; Nair, A.; Weng, H.; Tsai, Y.T.; Hu, Z.; Tang, L. Intraocular pressure changes: An important determinant of the biocompatibility of intravitreous implants. PLOS ONE 2011, 6, e28720. [CrossRef]

28. Macaya, D.; Spector, M. Injectable hydrogel materials for spinal cord regeneration: A review. Biomed. Mater. $2012,7,012001$. [CrossRef]

29. Hu, W.; Wang, Z.; Xiao, Y.; Zhang, S.; Wang, J. Advances in crosslinking strategies of biomedical hydrogels. Biomater. Sci. 2019, 7, 843-855. [CrossRef]

30. Zheng, J.; Smith Callahan, L.A.; Hao, J.; Guo, K.; Wesdemiotis, C.; Weiss, R.; Becker, M.L. Strain-promoted cross-linking of PEG-based hydrogels via copper-free cycloaddition. ACS Macro Lett. 2012, 1, 1071-1073. [CrossRef]

31. Donati, S.; Caprani, S.M.; Airaghi, G.; Vinciguerra, R.; Bartalena, L.; Testa, F.; Mariotti, C.; Porta, G.; Simonelli, F.; Azzolini, C. Vitreous substitutes: The present and the future. Biomed. Res. Int. 2014, 2014, 351804. [CrossRef]

32. Martens, T.F.; Remaut, K.; Deschout, H.; Engbersen, J.F.; Hennink, W.E.; van Steenbergen, M.J.; Demeester, J.; De Smedt, S.C.; Braeckmans, K. Coating nanocarriers with hyaluronic acid facilitates intravitreal drug delivery for retinal gene therapy. J. Control. Release 2015, 202, 83-92. [CrossRef]

33. Duan, W.; Chang, Y.; Li, R.; Xu, Q.; Lei, J.; Yin, C.; Li, T.; Wu, Y.; Ma, Q.; Li, X. Curcumin inhibits hypoxia inducible factor$1 \alpha$-induced epithelial-mesenchymal transition in HepG2 hepatocellular carcinoma cells. Mol. Med. Rep. 2014, 10, 2505-2510. [CrossRef]

34. Shan, B.; Schaaf, C.; Schmidt, A.; Lucia, K.; Buchfelder, M.; Losa, M.; Kuhlen, D.; Kreutzer, J.; Perone, M.J.; Arzt, E.; et al. Curcumin suppresses HIF1A synthesis and VEGFA release in pituitary adenomas. J. Endocrinol. 2012, 214, 389-398. [CrossRef] [PubMed]

35. Cao, Z.; He, S.; Peng, Y.; Liao, X.; Lu, H. Nanocurcumin Inhibits Angiogenesis via Down-regulating hif1a/VEGF-A Signaling in Zebrafish. Curr. Neurovascular Res. 2020, 17, 147-154. [CrossRef] [PubMed]

36. Davis, B.M.; Pahlitzsch, M.; Guo, L.; Balendra, S.; Shah, P.; Ravindran, N.; Malaguarnera, G.; Sisa, C.; Shamsher, E.; Hamze, H.; et al. Topical Curcumin Nanocarriers are Neuroprotective in Eye Disease. Sci. Rep. 2018, 8, 11066. [CrossRef] [PubMed] 
37. Deng, Y.I.; Verron, E.; Rohanizadeh, R. Molecular Mechanisms of Anti-metastatic Activity of Curcumin. Anticancer Res. 2016, 36, 5639-5647. [CrossRef] [PubMed]

38. Wilken, R.; Veena, M.S.; Wang, M.B.; Srivatsan, E.S. Curcumin: A review of anti-cancer properties and therapeutic activity in head and neck squamous cell carcinoma. Mol. Cancer 2011, 10, 12. [CrossRef] [PubMed]

39. Pescosolido, N.; Giannotti, R.; Plateroti, A.M.; Pascarella, A.; Nebbioso, M. Curcumin: Therapeutical potential in ophthalmology. Planta Med. 2014, 80, 249-254. [CrossRef] [PubMed]

40. Peddada, K.V.; Brown, A.; Verma, V.; Nebbioso, M. Therapeutic potential of curcumin in major retinal pathologies. Int. Ophthalmol. 2019, 39, 725-734. [CrossRef] [PubMed]

41. Giordano, A.; Tommonaro, G. Curcumin and cancer. Nutrients 2019, 11, 2376. [CrossRef]

42. Lu, C.; Song, E.; Hu, D.-N.; Chen, M.; Xue, C.; Rosen, R.; McCormick, S.A. Curcumin induces cell death in human uveal melanoma cells through mitochondrial pathway. Curr. Eye Res. 2010, 35, 352-360. [CrossRef]

43. Doggui, S.; Sahni, J.K.; Arseneault, M.; Dao, L.; Ramassamy, C. Neuronal uptake and neuroprotective effect of curcumin-loaded PLGA nanoparticles on the human SK-N-SH cell line. J. Alzheimers Dis. 2012, 30, 377-392. [CrossRef]

44. Wisotzki, E.I.; Hennes, M.; Schuldt, C.; Engert, F.; Knolle, W.; Decker, U.; Kas, J.A.; Zink, M.; Mayr, S.G. Tailoring the material properties of gelatin hydrogels by high energy electron irradiation. J. Mater. Chem. B 2014, 2, 4297-4309. [CrossRef] [PubMed]

45. Bubnis, W.A.; Ofner III, C.M. The determination of $\epsilon$-amino groups in soluble and poorly soluble proteinaceous materials by a spectrophotometrie method using trinitrobenzenesulfonic acid. Anal. Biochem. 1992, 207, 129-133. [CrossRef]

46. Saito, H.; Murabayashi, S.; Mitamura, Y.; Taguchi, T. Characterization of alkali-treated collagen gels prepared by different crosslinkers. J. Mater. Sci. Mater. Med. 2008, 19, 1297-1305. [CrossRef]

47. Astete, C.E.; Sabliov, C.M. Synthesis and characterization of PLGA nanoparticles. J. Biomater. Sci. Polym. Ed. 2006, 17, 247-289. [CrossRef]

48. Yallapu, M.M.; Gupta, B.K.; Jaggi, M.; Chauhan, S.C. Fabrication of curcumin encapsulated PLGA nanoparticles for improved therapeutic effects in metastatic cancer cells. J. Colloid Interface Sci. 2010, 351, 19-29. [CrossRef]

49. Bisht, S.; Feldmann, G.; Soni, S.; Ravi, R.; Karikar, C.; Maitra, A.; Maitra, A. Polymeric nanoparticle-encapsulated curcumin ("nanocurcumin"): A novel strategy for human cancer therapy. J. Nanobiotechnol. 2007, 5, 3. [CrossRef]

50. Posadowska, U.; Parizek, M.; Filova, E.; Wlodarczyk-Biegun, M.; Kamperman, M.; Bacakova, L.; Pamula, E. Injectable nanoparticleloaded hydrogel system for local delivery of sodium alendronate. Int. J. Pharm. 2015, 485, 31-40. [CrossRef]

51. Schulz, A.; Wahl, S.; Rickmann, A.; Ludwig, J.; Stanzel, B.V.; von Briesen, H.; Szurman, P. Age-Related Loss of Human Vitreal Viscoelasticity. Transl. Vis. Sci. Technol. 2019, 8, 56. [CrossRef]

52. Wang, H.; Wu, Y.; Cui, C.; Yang, J.; Liu, W. Antifouling super water absorbent supramolecular polymer hydrogel as an artificial vitreous body. Adv. Sci. 2018, 5, 1800711. [CrossRef]

53. Schnichels, S.; Schneider, N.; Hohenadl, C.; Hurst, J.; Schatz, A.; Januschowski, K.; Spitzer, M.S. Efficacy of two different thiol-modified crosslinked hyaluronate formulations as vitreous replacement compared to silicone oil in a model of retinal detachment. PLoS ONE 2017, 12, e0172895. [CrossRef] [PubMed]

54. Kamata, H.; Li, X.; Chung, U.I.; Sakai, T. Design of Hydrogels for Biomedical Applications. Adv. Healthc. Mater. 2015, 4, 2360-2374. [CrossRef] [PubMed]

55. Gao, F.; Xu, Z.; Liang, Q.; Li, H.; Peng, L.; Wu, M.; Zhao, X.; Cui, X.; Ruan, C.; Liu, W. Osteochondral Regeneration with 3D-Printed Biodegradable High-Strength Supramolecular Polymer Reinforced-Gelatin Hydrogel Scaffolds. Adv. Sci. 2019, 6, 1900867. [CrossRef] [PubMed]

56. Thavarajah, D.; De Lacy, P.; Hussain, R.; Redfern, R.M. Postoperative cervical cord compression induced by hydrogel (DuraSeal): A possible complication. Spine 2010, 35, E25-E26. [CrossRef]

57. Dhanasingh, A.; Salber, J.; Moeller, M.; Groll, J. Tailored hyaluronic acid hydrogels through hydrophilic prepolymer cross-linkers. Soft Matter 2010, 6, 618-629. [CrossRef]

58. Collins, M.N.; Birkinshaw, C. Morphology of crosslinked hyaluronic acid porous hydrogels. J. Appl. Polym. Sci. 2011, 120, 1040-1049. [CrossRef]

59. Luo, Y.; Kirker, K.R.; Prestwich, G.D. Cross-linked hyaluronic acid hydrogel films: New biomaterials for drug delivery. J. Control. Release 2000, 69, 169-184. [CrossRef]

60. Karadağ, E.; Üzüm, Ö.B.; Saraydin, D. Swelling equilibria and dye adsorption studies of chemically crosslinked superabsorbent acrylamide/maleic acid hydrogels. Eur. Polym. J. 2002, 38, 2133-2141. [CrossRef]

61. Huang, X.; Chau, Y. Intravitreal nanoparticles for retinal delivery. Drug Discov. Today 2019, 24, 1510-1523. [CrossRef]

62. Collin, E.C.; Grad, S.; Zeugolis, D.I.; Vinatier, C.S.; Clouet, J.R.; Guicheux, J.J.; Weiss, P.; Alini, M.; Pandit, A.S. An injectable vehicle for nucleus pulposus cell-based therapy. Biomaterials 2011, 32, 2862-2870. [CrossRef] [PubMed]

63. Schwartz, D.M.; Shuster, S.; Jumper, M.D.; Chang, A.; Stern, R. Human vitreous hyaluronidase: Isolation and characterization. Curr. Eye Res. 1996, 15, 1156-1162. [CrossRef]

64. Afify, A.M.; Stern, M.; Guntenhoner, M.; Stern, R. Purification and characterization of human serum hyaluronidase. Arch. Biochem. Biophys. 1993, 305, 434-441. [CrossRef]

65. Perez-Tamayo, R. Pathology of collagen degradation. A review. Am. J. Pathol. 1978, 92, 508-566. [PubMed]

66. Shahani, K.; Panyam, J. Highly loaded, sustained-release microparticles of curcumin for chemoprevention. J. Pharm. Sci. 2011, 100, 2599-2609. [CrossRef] 
67. Shahani, K.; Swaminathan, S.K.; Freeman, D.; Blum, A.; Ma, L.; Panyam, J. Injectable sustained release microparticles of curcumin: A new concept for cancer chemoprevention. Cancer Res. 2010, 70, 4443-4452. [CrossRef] [PubMed]

68. Tønnesen, H.H.; Karlsen, J. Studies on curcumin and curcuminoids. Zeitschrift für Lebensmittel-Untersuchung und Forschung 1985, 180, 402-404. [CrossRef] [PubMed]

69. Anand, P.; Kunnumakkara, A.B.; Newman, R.A.; Aggarwal, B.B. Bioavailability of curcumin: Problems and promises. Mol. Pharm. 2007, 4, 807-818. [CrossRef]

70. Alshamrani, M.; Sikder, S.; Coulibaly, F.; Mandal, A.; Pal, D.; Mitra, A.K. Self-assembling topical nanomicellar formulation to improve curcumin absorption across ocular tissues. AAPS PharmSciTech 2019, 20, 1-16. [CrossRef]

71. Chibhabha, F.; Yang, Y.; Ying, K.; Jia, F.; Zhang, Q.; Ullah, S.; Liang, Z.; Xie, M.; Li, F. Non-invasive optical imaging of retinal $\mathrm{A} \beta$ plaques using curcumin loaded polymeric micelles in APP swe/PS1 $\Delta \mathrm{E} 9$ transgenic mice for the diagnosis of Alzheimer's disease. J. Mater. Chem. B 2020, 8, 7438-7452. [CrossRef] [PubMed]

72. Zhou, Y.; Cai, Y.; Hu, X.; Long, Y. Temperature-responsive hydrogel with ultra-large solar modulation and high luminous transmission for "smart window" applications. J. Mater. Chem. A 2014, 2, 13550-13555. [CrossRef]

73. Boettner, E.A.; Wolter, J.R. Transmission of the ocular media. Investig. Ophthalmol. Vis. Sci. 1962, 1, 776-783. 